Research Article

\title{
Metabolic Syndrome and Erectile Dysfunction
}

Alice Walton ${ }^{1,{ }^{\dagger}}$, Mustafa Faruk Usta ${ }^{2,{ }^{+}}$, Melissa Wong ${ }^{1}$, Wayne Hellstrom ${ }^{1,}{ }^{*}$

1. Tulane University School of Medicine, Department of Urology, New Orleans, LA USA; E-Mails: awalton2@tulane.edu; mwong5@tulane.edu; whellst@tulane.edu

2. Akdeniz University School of Medicine, Department of Urology, Antalya, Turkey; E-Mail: mustafafarukusta@gmail.com

+ These authors contributed equally to this work.

* Correspondence: Wayne Hellstrom; E-Mail: whellst@tulane.edu

Academic Editor: Gerhard Litscher

Special Issue: Metabolic Syndrome

OBM Integrative and Complementary Medicine 2021, volume 6 , issue 4

doi:10.21926/obm.icm.2104042
Received: August 01, 2021

Accepted: October 13, 2021

Published: November 02, 2021

\section{Abstract}

Metabolic syndrome (MetS) is considered a risk factor for erectile dysfunction (ED), and ED is almost three times more prevalent in men with MetS. Vascular pathologies are a significant factor for the development of ED, and many experts suggest endothelial dysfunction (EnD) as a likely explanation for the association between ED and MetS. Studies also show that corporal vascular and trabecular smooth muscle dysfunction leads ultimately to corporal venoocclusive dysfunction. Different functional system abnormalities, such as nervous degenerations, hormonal insufficiencies, and metabolic factors (e.g., hyperlipidemia, advanced glycation end products), are also likely involved in the pathophysiological pathways. Autonomic neuropathy is also commonly encountered in patients and animal models of MetS. From another perspective, low testosterone levels may be predictive of MetS. Several studies concluded that components of MetS, such as high blood pressure, obesity, hyperinsulinemia, T2DM, hyperglycemia, hypertriglyceridemia, elevated C-Reactive protein, and low HDL levels, were all associated with decreased serum testosterone levels. Lifestyle modification, such as

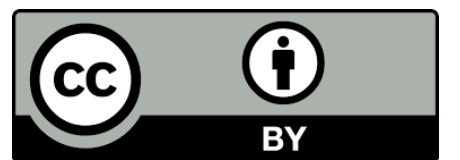

(C) 2021 by the author. This is an open access article distributed under the conditions of the Creative Commons by Attribution License, which permits unrestricted use, distribution, and reproduction in any medium or format, provided the original work is correctly cited. 
exercise and diet, are the first-line treatment for MetS. Studies have found that a $10 \%$ weight loss has been shown to significantly increase IIEF- 5 scores. Exercise was also shown to increase endothelial-derived NO and decrease oxidative stress, resulting in a lower risk of developing ED in physically active men. Metformin combined with PDE5 inhibitors is a promising treatment approach, although with limited research.

\section{Keywords}

Metabolic syndrome; erectile dysfunction; hypertension; insulin resistance; endothelial dysfunction

\section{Introduction}

Metabolic syndrome (MetS) is a cluster of metabolic abnormalities most simply defined by four central features: insulin resistance, visceral adiposity, atherogenic dyslipidemia, and endothelial dysfunction [1]. MetS is postulated to be most closely linked to the development of insulin resistance by increasing adipose tissue and abdominal obesity [2]. In the wake of a worldwide obesity epidemic, rates of MetS are steadily increasing. According to the United States National Health and Nutrition Examination Survey, more than 1 in 3 adults have MetS [3]. Although approximately $40 \%$ of adults over the age of 40 have MetS, patients are largely asymptomatic [3].

MetS has been reported to be a risk factor for the development of erectile dysfunction (ED) [4, 5]. ED is the inability to achieve and sustain a sufficient erection for satisfactory penetrative intercourse, and it affects 5-20\% of men worldwide [4]. The prevalence of ED is two times greater in MetS patients than in controls $[4,6]$. Though the exact mechanism is not well understood, the close association between MetS and cardiovascular disease (CVD) is hypothesized to play a major role in the development of ED [7]. Increasing understanding of these associations infers that obesity, CVD, type 2 diabetes mellitus (T2DM), and ED should not be regarded as separate diseases in middle-aged and elderly men but rather all part of the same syndrome [7].

The aim of this review is to describe and summarize the association between MetS and ED on a preclinical and clinical level. A summary of current treatment options will also be reviewed.

\section{Materials and Methods}

The authors performed a comprehensive literature search on PubMed. Searched keywords included "Erectile dysfunction" and "Metabolic syndrome." Applicable articles were identified and reviewed. Additional articles were identified from their reference lists. Review of these articles provided the sought-after data.

\section{Background on Metabolic Syndrome}

The concept of MetS was first recognized by Reaven in 1988, which he termed 'syndrome $X^{\prime}$ [8]. Reavan hypothesized that MetS, through the mechanism of insulin resistance, was a central component of the development of T2DM and CVD. Today, MetS is typically defined as one or more 
of the following conditions: insulin resistance, low HDL cholesterol, hypertriglyceridemia, abdominal obesity, and hypertension [3, 9].

The biology of MetS begins with abdominal obesity and adipose tissue. Adipose tissue produces adiponectin, which increases appetite, insulin sensitivity, and pancreatic beta-cell survival and functionality [9]. However, contrary to the expected increase in adiponectin as adipose tissue increases, lower circulating levels of adiponectin are found in obese subjects compared to lean subjects [10]. In accordance with these findings, levels of adiponectin mRNA are lower in the adipose tissue of obese subjects. These findings suggest that an increase in fat mass leads to the dysregulation of adiponectin and eventually the development of insulin resistance. Visceral adiposity has been shown to be a strong negative predictor of adiponectin and likely identities the relationship between obesity and the development of MetS. While the causation is unclear, increased expression of tumor necrosis factor- $\alpha$ (TNF- $\alpha$ ) in obese individuals suggests that it may be the adipocytokine that effectively suppresses adiponectin levels as fat mass increases [10].

Additionally, adipose tissue releases non-esterified free fatty acids that can accumulate in other sites such as the liver and muscles, further predisposing the patient to insulin resistance and dyslipidemia [3]. Separately, adipose tissue can produce a variety of adipokines that can affect insulin resistance and CVD risk factors [3]. This adipokines production, in combination with hypertension and dyslipidemia, cultivates prothrombotic and proinflammatory states. Studies have revealed that MetS is closely associated with elevated levels of CRP as well as with proinflammatory cytokines including interleukin-1 $\beta$ (IL-1 $\beta$ ), interleukin-6 (IL-6), and TNF- $\alpha$. Furthermore, macrophage infiltration has also been shown to cause insulin resistance $[11,12]$.

First-line treatments for MetS are therapeutic lifestyle modifications (TLM), such as exercise and diet $[3,9]$. According to The Diabetes Prevention Program regimen, TLM have a much greater influence on MetS than pharmacologic treatments [3]. However, statins, angiotensin-converting enzyme inhibitors, and aspirin can be used as adjunct therapy to TLM.

It should be noted here that throughout the years, several definitions of MetS have been proposed by various organizations, such as the World Health Organization (WHO), International Diabetes Foundation (IDF), and National Cholesterol Education Program (NCEP) (Table 1) [9]. While there are similarities between each of the definitions, the laboratory values and the number of positive criteria for the definition of MetS vary between these organizations [13].

Table 1 Definitions of MetS proposed World Health Organization (WHO), International Diabetes Foundation (IDF) and National Cholesterol Education Program (NCEP) [9].

\begin{tabular}{|c|c|c|}
\hline WHO 1999 & IDF 2006 & NCEP 2005 \\
\hline $\begin{array}{l}\text { The presence of insulin resistance } \\
\text { or glucose }>6.1 \mathrm{mmol} / \mathrm{L}, 2 \mathrm{hr} \\
\text { glucose }>7.8 \mathrm{mmol} \text { along with the } \\
\text { presence any two or more of the } \\
\text { following: }\end{array}$ & $\begin{array}{l}\text { Waist circumference }>94 \mathrm{~cm} \\
\text { (men) or } 80 \mathrm{~cm} \text { (women) along } \\
\text { with the presence any two or } \\
\text { more of the following: }\end{array}$ & $\begin{array}{l}\text { Presence of any three of more of } \\
\text { the following: }\end{array}$ \\
\hline $\begin{array}{l}\text { 1. Waist/hip ratio }>0.9 \text { (men) } \\
\text { or }>0.85 \text { (women) or } \mathrm{BMI}>30 \\
\mathrm{~kg} / \mathrm{m}^{2}\end{array}$ & $\begin{array}{l}\text { 1. Blood glucose greater than } \\
5.6 \mathrm{mmol} / \mathrm{L} \text { or diagnosed } \\
\text { diabetes }\end{array}$ & $\begin{array}{l}\text { 1. Blood glucose greater than } \\
5.6 \mathrm{mmol} / \mathrm{L} \text { or drug } \\
\text { treatment for elevated } \\
\text { blood glucose }\end{array}$ \\
\hline
\end{tabular}



2. Blood pressure $>140 / 90$ $\mathrm{mmHg}$

3. HDL cholesterol $<0.9 \mathrm{mmol} / \mathrm{L}$ in men, $<1.0 \mathrm{mmol} / \mathrm{L}$ in women

4. Triglycerides $>1.7 \mathrm{mmol} / \mathrm{L}$
2. Blood pressure $>130 / 85$ $\mathrm{mmHg}$ or drug treatment for hypertension

3. HDL cholesterol $<1.0$ $\mathrm{mmol} / \mathrm{L}$ (men) or $<1.3$ $\mathrm{mmol} / \mathrm{L}$ (women) or drug treatment for low HDL-C

4. Blood triglycerides $>1.7$ $\mathrm{mmol} / \mathrm{L}$ or drug treatment for elevated triglycerides
2. Waist $>102 \mathrm{~cm}$ (men) or $>88$ $\mathrm{cm}$ (women)

3. Blood pressure $>130 / 85$ $\mathrm{mmHg}$ or drug treatment for hypertension

4. $\mathrm{HDL}$ cholesterol $<1.0 \mathrm{mmol} / \mathrm{L}$ (men) or $<1.3 \mathrm{mmol} / \mathrm{L}$ (women) or drug treatment for low HDL-C

5. Blood triglycerides $>1.7$ $\mathrm{mmol} / \mathrm{L}$ or drug treatment for elevated triglycerides

\section{Basic Science Evidence for the Relationship Between ED and MetS}

Erectile Dysfunction (ED) has been defined as the inability to attain or maintain penile erection for satisfactory sexual intercourse. ED is a prevalent disease affecting more than $\mathbf{1 5 0}$ million men worldwide [14]. ED may be attributed to several etiologies, and its prevalence increases with age, particularly over the age of 60 years $[15,16]$. It has been reported that various etiologies, including neurogenic, hormonal, drug-related, systemic, and psychogenic diseases and aging, play crucial roles in the development of ED [17]. Specifically, endothelium-dependent impairment as a result of decreased bioavailability of nitric oxide (NO), increased sympathetic nerve activity resulting in enhanced myogenic tone within the cavernosal smooth muscle cells, and atherosclerotic luminal occlusion leading to reduced arterial inflow are the main pathophysiological mechanisms for arteriogenic ED [15-17].

Recently, several authors have suggested that co-managing ED and MetS should be considered as a therapeutic strategy; therefore, it is necessary to account for the risk relationship on a mechanistic basis. Many experts suggest endothelial dysfunction (EnD) is a likely explanation for the association between ED and MetS [18]. Current experimental studies have revealed that multiple pathophysiological pathways may play important roles in the relationship between ED and MetS beyond simply EnD. For instance, studies show that corporal vascular and trabecular smooth muscle dysfunction leads ultimately to corporal veno-occlusive dysfunction $[19,20]$. Different functional system abnormalities, such as nervous degenerations, hormonal insufficiencies, and metabolic factors (e.g., hyperlipidemia, advanced glycation end products), are also likely involved in the pathophysiological pathways [18-21].

\subsection{Metabolic Diseases, Obesity, and High Blood Pressure}

Metabolic dysfunction is an important link between MetS and ED. In general, metabolic diseases are described as having system-wide effects on glucose and oxidative mechanisms. During a state of hyperglycemia, there is an increased generation of advanced glycation end products (AGEs) in erectile tissue, which causes oxidative stress, decreased production of NO, and ultimately the 
development of ED [22-24]. In an animal model of DM, hyperglycemia increased O-GlycNAc modification of endothelial nitric oxide synthase (eNOS) in the penis, which prevented phosphorylation at the enzymatic level. This event causes an impairment in erectile response [25]. Additionally, obesity has been accepted as a key component of MetS, which in turn causes oxidative stress, inflammation, and insulin and leptin resistance [26].

Recently, measurements of collagen/endothelium contents in penile tissue obtained from Zucker Fatty (ZF) and Zucker Lean (ZL) rats provided insight into the relationship between obesity and ED [27]. Intracavernosal pressure after cavernosal nerve stimulation was shown to be significantly lower in ZF rats than in ZL rats. Similarly, contents of endothelium and smooth muscle were reduced in $Z F$ rats when compared to $Z L$ rats.

High blood pressure has similarly been attributed to causing ED. A recent preclinical study reported significantly lower erectile capacity in spontaneously hypertensive rats than in the control groups [28]. Additionally, cavernosal smooth muscle content, nNOS, and endothelial factor (CD31) content was significantly lower in hypertensive rats.

\subsection{Vascular Pathologies}

Vascular pathologies are a significant factor for the development of ED. This is relevant in the discussion of ED and MetS as major cardiometabolic co-morbidities, such as diabetes mellitus, high blood pressure, hypercholesterolemia, and obesity, associated with EnD [29]. EnD, commonly encountered in vascular pathologies, has been defined as either decreased responsiveness to vasodilators or increased sensitivity to vasoconstrictors [30]. Additionally, EnD also includes some pathological conditions such as altered anticoagulation and anti-inflammatory reactions, decreased modulation of vascular growth, and impaired remodeling of vascular tissue. There are several basic science studies investigating the temporal relationship between ED and EnD that demonstrate conflicting results. In a mouse model with type-1 DM, endothelium-dependent vasorelaxation was decreased in both the penis and aorta at 4 and 6 weeks after DM development [31]. In another study using a rat model with type-1 DM, there was decreased endothelial vasorelaxation and increased oxidative stress seen in the corporal sinusoids and aorta 8 weeks after DM development [32]. Dietary manipulation models showed similar results, supporting the concept that EnD plays an important role in ED development. In a high-fructose feeding model, decreased endotheliumdependent vasorelaxation of both the aorta and cavernosal tissue occurred through the impaired peroxisome proliferator-activated receptor- $\gamma$ signaling and increased caveolin-1 expression [33]. In a mouse model of hypercholesterolemia, endothelial function was disrupted in addition to increased production of reactive oxygen species and activation of the renin -angiotensin system in both the aorta and cavernosal tissue. In a rabbit model in which the rabbits were fed high fat for 6 weeks, there was reduced endothelium-dependent vasorelaxation of the thoracic aorta, renal artery, and corpus cavernosum [34].

In contrast with the aforementioned results, various studies revealed evidence that the detrimental effect of co-morbid factors were focused on penile vasculature, rather than the systemic vasculature. For instance, in obese Zucker rats, a genetic model of insulin resistance, the decrease of endothelial-dependent vasorelaxation was only observed in the dorsal penile artery but not in the coronary artery at $>17$ weeks of age [35]. In several other diet manipulation studies, it has been shown that while ED developed in the early period of the experiments, impairment of 
endothelium-dependent vasorelaxation of the systemic vasculature was observed only during late periods of the studies [35-40]. ED developed between 16-20 weeks of age [41] and impaired coronary vasodilator response to acetylcholine was observed after 28 weeks of age [42].

These results suggest that the development of EnD in different vascular tissues appears to be time-dependent. These results support the artery size hypothesis: arteries with small diameters are more greatly affected by lumen narrowing, whereas vessels with larger diameter can compensate more narrowing from plaque deposition without significant changes in blood flow [43]. Therefore, the small diameter of cavernosal and helicine arteries $(1-2 \mathrm{~mm})$ and erectile sinusoids tend to early development of EnD and atherosclerosis. This would explain why ED commonly precedes CVD.

In another experimental study, $\mathrm{Li}$ et al. aimed to investigate the underlying mechanism of metabolic syndrome-related ED [4]. In their rigorous study, Sprague Dawley rats were fed a high-fat diet for 6 months. Erectile capacity and the penile content of erectile physiology-related molecules, such as cyclic guanosine monophosphate (cGMP), were investigated. The results revealed that erectile capacity and concentration of cGMP were significantly decreased in rats with MetS. Additionally, the expression levels of $\mathrm{p} 110 \alpha, \mathrm{p}$-Akt1, and eNOS were reduced in the MetS rats. Activation of the PI3K/Akt/eNOS signaling cascade reversed these changes, suggesting that the signaling pathways are involved in MetS-associated ED [4].

In another MetS-related rat ED model, the authors compared the influence of Kv7 channel activation on smooth muscle relaxation in penile arteries and corpora cavernosa in control rats and in rats with MetS. In this in vitro study, Kv7 channels played a crucial role in erectile function and contributed to the pathophysiology of MetS-related ED, which should be considered as a possible link between MetS and ED [44].

\subsection{Cavernosal Smooth Muscle Dysfunction}

Several studies reveal the role of cavernosal smooth muscle contractility in MetS-related ED. In an in vitro rat model of type-1 DM, Elçioğlu et al. reported that maximum contraction of the cavernousal smooth muscle after exposure to phenylephrine was reduced by about $50 \%$ in diabetic penile tissue [45]. Similarly, Carneiro et al. found that TNF- $\alpha$-infused mice displayed increased cavernosal smooth muscle contractility and decreased nonadrenergic-noncholinergic (NANC)induced relaxation associated with eNOS and neural NO synthase (nNOS) gene expression. These changes suggest that TNF- $\alpha$ and chronic inflammation play a role in ED [46]. Kovanecz also demonstrated that in vitro relaxation of corporal tissue in obese Zucker rats was significantly less than that from lean Zucker control rats [47]. Molecular studies revealed that there was a significant decrease in smooth muscle content and smooth muscle cell/collagen ratio. Furthermore, there was also significant apoptosis in the media of the dorsal artery of obese Zucker rats when compared to control rats [47].

\subsection{Neural Dysfunction and Degeneration}

Autonomic neuropathy is commonly encountered in patients and animal models of MetS. According to the recent literature, MetS is associated with autonomic sympathetic overactivity. Animal models of MetS do not show marked changes in cavernosal nerve density or nerve-evoked smooth muscle activity. Recent reports provided some data revealing that regeneration of nitrergic nerves after crush injury in rats with MetS was impaired compared to control rats [48]. Furthermore, 
nitrergic dysfunction and impaired neuronal NO signaling, due to oxidative stress and nNOS uncoupling in penile arteries, were observed in insulin-resistant, obese Zucker rats [49].

\subsection{Hypogonadism}

Interestingly, low testosterone levels may be predictive of later development of metabolic disease and T2DM [50-52]. In animal models, androgens were important for the development, maturation, and preservation of the penile pelvic sympathetic neurons $[53,54]$. Moreover, castrated rodents with low testosterone levels demonstrated alterations in endothelial morphology, decreased trabecular smooth muscle content, increased extracellular matrix deposition, and loss of elastic fibers within the tunica albuginea $[55,56]$. Finally, increased adipocyte accumulation in the subtunical region of cavernosal tissue in castrated rats leads to veno-occlusive dysfunction [37]. In several studies, all of the aforementioned changes in corporal structure and function were preserved or reversed after testosterone replacement therapy [55, 57-59]. Other recent basic science studies reported that androgen deficiency led to a significant decrease in the expression and enzymatic activity of eNOS, nNOS, and phosphodiesterase type 5 (PDE5) and an increase in alphaadrenergic responsiveness in the penis $[58,60,61]$. The results of a well-designed animal model revealed that testosterone replacement therapy reduced visceral obesity and increased penile responsiveness to PDE5 inhibitors [62].

Musicki et al. conducted a comprehensive literature review to evaluate the evidence basis for a pathophysiologic link between ED and MetS, defining the risk relationship, and suggested potential directions for novel therapeutic alternatives [18]. The authors concluded that further basic science studies are needed to evaluate the critical role of endothelial cells, which supposedly underline the temporal relationship between penile and systemic beds in response to cardiometabolic risk factors. Furthermore, they conclude that smooth muscle cell dysfunction is not well described and should be investigated in more detail. Similarly, well-designed preclinical studies on autonomic dysfunction are necessary to determine the exact mechanism of how autonomic neuropathy affects pathophysiological pathways and tissue morphology, causing to ED and EnD as well. On the other hand, the authors reported that the link between low testosterone and subsequent development of ED and MetS is strongly supported by basic science data. Finally, the authors described that though there are several studies suggesting the possible link between ED and MetS, more detailed and well-designed studies will help to broaden our understanding about the temporal and causal relationship of ED development in MetS.

\section{Relationship between MetS and ED: Clinical Data}

As mentioned, MetS is a combination of disease processes that affect erectile function [14]. Studies have documented that the prevalence of MetS in the United States is about 35\%. The significance of this prevalence reflects the association between MetS and ED [14].

ED is almost three times more prevalent in men with MetS [13]. On the other hand, it has also been reported that there is a direct relationship between several components of MetS such as obesity, high blood pressure, T2DM, and hypertriglyceridemia. Esposito et al. described that ED prevalence was three times higher in men who had three or more components of MetS [63]. Similar results reported by Bal et al. demonstrated that ED prevalence increased with the number of MetS components [64]. The odds ratio of increased waist circumference (WC) was 1.94, while it was 2.97 
and 3.38 for increased WC and abnormal HDL and increased WC, abnormal HDL, and hypertriglyceridemia, respectively [64]. Furthermore, according to the Massachusetts Male Aging study data, the presence of MetS in those with a BMI $>25$ doubled the risk of the development of ED. The authors concluded ED could be predictive of MetS development in the non-obese population.

It is well established that MetS causes numerous cardiovascular risks. In fact, it has been reported that MetS itself or the presence of one to two of its features increases the risk of cardiovascular disease (CVD) and T2DM, which are directly related to the onset of ED [13]. For instance, it has been reported that men with four to five features of MetS had a 3.7-fold increase in coronary artery disease and a 24.5-fold increase in T2DM when compared to men without a MetS feature [65].

The same pathophysiological pathway that causes atherosclerotic and coronary artery disease in men affected by MetS may similarly impact the penile vascular tissue [66]. One study reported that the presence of arterial insufficiency-related ED was significantly associated with ischemic cardiac disease in men over the age of 40 [67]. Similarly, Araujo et al. found ED was associated with an increased risk of CVD mortality. In another study, men with ED had a doubled risk of myocardial infarction when compared to men without ED [68]. In a recent study, the relationship between cardiovascular health and EnD/ED was assessed by a flow-mediated dilation test [69]. The results showed that flow-mediated dilation was higher in men without ED and higher in men with good cardiovascular health. The authors concluded that poor cardiovascular health is associated with future ED while maintaining high cardiovascular health leads to improvement of quality of life. It has been suggested that there is a role for ED in cardiovascular risk prediction and assessment. There may be a critical benefit in evaluating cardiovascular risk in young men with moderate to severe ED with no known history of diabetes, CVD, or CAD [66].

As mentioned previously, another important pathophysiological mechanism commonly observed in patients with MetS is the development of EnD. Components of MetS, including insulin resistance, hyperglycemia, and the subsequent development of AGEs, free fatty acids, and chronic inflammation, ultimately leads to EnD. Similarly, Giugliano et al. found that obese men (BMI > 25) had higher circulating concentrations of IL-6, interleukin-8 (IL-8), interleukin-18 (IL-18), and Creactive protein (CRP) when compared to non-obese men [70]. These findings, along with impaired platelet aggregation in response to L-arginine, suggested EnD. In obese men with ED, the study found higher CRP and endothelial dysfunction than in obese men without ED. In the presence of $\mathrm{EnD}$ and atherosclerosis, there is a significant decrease in NO production and bioavailability that has a critical role in both endothelial and erectile disfunction [1]. There are several other important consequences of hyperglycemia, such as increased production of free radicals (e.g., superoxide anion), which inactivates NO. Furthermore, hyperinsulinemia and EnD in T2DM increase levels of the vasoconstrictor endothelin-1 (ET-1) [71].

The Look AHEAD (Action for Health in Diabetes) study aimed to determine the prevalence and correlates of ED in obese men with T2DM [72]. A total of 373 men were assessed by the International Index for Erectile Dysfunction (IIEF), self-reported use of PDE5 inhibitors, laboratory measures of adiposity, cardiometabolic parameters, and exercise-fitness criteria. The analysis concluded that obese men with T2DM and cardiovascular risk factors have a significant association with ED. Moreover, fitness and exercise were found to have protective effect on the development of ED. Weinberg and colleagues performed a cross-sectional analysis in 3,306 male individuals and investigated the association between diabetic severity and the presence of MetS with ED. The 
results indicated that poor glycemic control, increased insulin resistance, and the presence of MetS is associated with an increased risk of ED [73].

There is evidence that low levels of testosterone are significantly associated with the prevalence of MetS. Several studies concluded that components of MetS, such as high blood pressure [74], obesity [75], hyperinsulinemia [76], T2DM [77], hyperglycemia [78], hypertriglyceridemia [79], elevated CRP [80], and low HDL levels were all associated with decreased serum testosterone levels. Corona and colleagues demonstrated that low testosterone levels were associated with severe ED, decreased libido and nocturnal erections, and reduction of sexual intercourse frequency [81]. All of these symptoms were more commonly observed in men over the age of 62 , suggesting that hypogonadism usually affects older men.

According to recent literature, there is perhaps a link between hypogonadism and MetS through leptin. Leptin is a $16-\mathrm{kDa}$ protein produced and secreted by adipocytes. It has been reported that leptin regulates energy intake and utilization via the hypothalamus. While leptin is directly associated with BMI, it is inversely associated with testosterone levels [80]. It has also been shown that visceral obesity, a very well-described feature of MetS, leads to hypogonadism through increased aromatase activity. Aromatase, an adipose enzyme, causes irreversible conversion of testosterone to estrogen [82].

\section{Treatment}

As previously mentioned, exercise and diet are the first-line treatment for MetS. Addressing lifestyle changes is important for ED as well, since doing so can help change the course of ED. Lifestyle factors that are modifiable include physical activity, obesity, and diet. Abdominal obesity and adipose tissue are key to the development of MetS. ED is more common in obese men, with one study showing a higher relative ratio of 1.7 in obese men compared to non-obese [83]. The positive effect of weight loss, either through dietary modifications or surgery, has been demonstrated in studies. Khoo et al. implemented a low-calorie diet for eight weeks and found that a $10 \%$ weight loss produced significantly increased IIEF-5 scores [84]. Patients who lost weight through bariatric surgery lost more weight than the non-surgery control group and had significantly increased IIEF-5 scores $p=0.0224$ [85].

At a molecular level, exercise appears to increase endothelial-derived NO, decrease oxidative stress, and increase endothelial progenitor cells (EPCS), which are regenerative. A meta-analysis manifested a lower risk of ED with moderate- and high-physical activity, with odds ratio 0.63 and 0.42 respectively [86]. The Massachusetts Male Aging Study (MMAS) followed 593 men, ages 40 to 70 years, with no prior history of ED, prostate cancer, heart disease, or diabetes for eight years. Physically active men showed a lower risk of developing ED, and obesity was found to be an independent predictor of ED [87].

Exercise is an effective and non-pharmacologic intervention against the development of ED. The impact of physical activity was reviewed by Gerbild et al., who included 10 articles in their review [88]. All of the studies implemented aerobic exercises of moderate intensity. The mean duration was 40 minutes per session and 120 to 300 minutes per week. They concluded that four sessions of moderate- to high-intensity training lasting 40 minutes each, corresponding to 160 minutes weekly for six months, improved erectile function. 
When it comes to diet, studies have focused on the Mediterranean diet, which consists of more fruits, vegetables, nuts, whole grains, and olive oil. More patients on the Mediterranean diet had an increased IIEF score compared to those on a control diet after two years [89]. It is postulated that this diet reduces coronary disease, oxidative stress, and inflammation.

An alternative approach to treatment is pharmacotherapy directed at the individual components of MetS. Specifically, treating dyslipidemia and insulin resistance are common approaches. 3hydroxy-3-methylglutaryl-coenzyme A (HMG-CoA) reductase inhibitors (statins) are a first-line medical therapy for hyperlipidemia and are protective of the vascular endothelium [90].

When it comes to improving insulin resistance, Metformin is an oral medication that has been used for decades in the treatment of T2DM. The major target molecule of metformin is AMPK, a molecule activated under an energy-deprived state and mediated effects on the endothelium, such as activating NOS, reducing oxidative stress, and suppressing endoplasmic reticulum stress. Jing et al. presented that metformin alters macrophage polarization, which counters the inflammatory state observed in obesity [91]. Vitale et al. demonstrated that metformin improves endothelialdependent vasodilation in patients with MetS [92]. He studied 65 patients with MetS who were randomized to metformin $500 \mathrm{mg}$ twice a day or placebo for three months. Patients who received metformin had significantly improved endothelium-dependent vasodilatation compared to placebo.

Metformin combined with PDE5 inhibitors is another promising treatment approach, although with limited research. Rey-Valzacchi et al. performed a prospective, randomized, double-blind study of treatment with metformin and sildenafil [93]. They theorized that PDE5 inhibitors require adequate levels of NO to be effective and insulin-resistant states have decreased NO levels, so metformin helps by reducing insulin resistance. They researched 30 non-diabetic men, randomized to two arms to receive metformin $850 \mathrm{mg}$ twice daily or a placebo in addition to sildenafil $100 \mathrm{mg}$ on demand. Those receiving metformin had a significant increase in IIEF-5 score at month 2 (IIEF-5: $17.0 \pm 6.0$ vs $14.3 \pm 3.9, P=.01$ ) and month 4 of treatment (IIEF-5: $19.8 \pm 3.8$ vs $14.3 \pm 3.9, P=.005$ ), with no changes in patients receiving placebo. The mean improvement in the 25-point IIEF-5 score on the metformin + sildenafil arm was 5.5 points versus 0.6 points in the placebo + sildenafil arm [93].

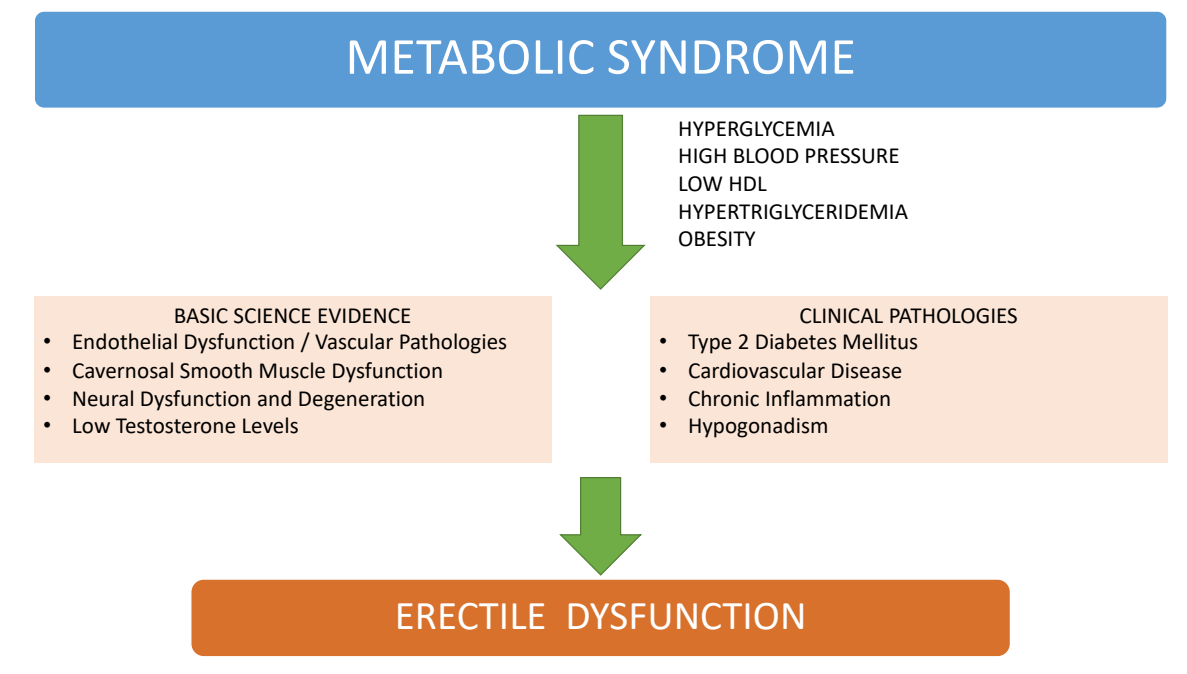

Figure 1 Possible relationship between basic science and clinical components of metabolic syndrome and erectile dysfunction. 


\section{Conclusions}

ED is the most common male sexual dysfunction. There is a body of evidence demonstrating that ED shares many risk factors with systemic diseases, including CVD and MetS. A majority of studies report that ED is linked to CVD. Both preclinical and clinical studies provide evidence that ED is a potential risk predictor for the development of future cardiac disease. Furthermore, various studies have revealed that ED is associated with MetS, insulin resistance, and poor glycemic control. It has been widely accepted that reducing the prevalence of obesity and improving management of T2DM will decrease the burden of ED in middle-aged- and older men. Increasing the public knowledge related to the relationship between ED and MetS may motivate the needed lifestyle changes in middle-aged and older men.

\section{Author Contributions}

Conception and design: Alice Walton, Mustafa Usta, Wayne Hellstrom; Acquisition of data: Alice Walton, Mustafa Usta, Melissa Wong; Analysis and interpretation of data: Alice Walton, Mustafa Usta; Drafting of manuscript: Alice Walton, Mustafa Usta, Melissa Wong; Revising it for intellectual content: Alice Walton, Mustafa Usta, Wayne Hellstrom; Final approval of completed manuscript: Wayne Hellstrom.

\section{Competing Interests}

The authors have declared that no competing interests exist.

\section{References}

1. Huang PL. A comprehensive definition for metabolic syndrome. Dis Model Mech. 2009; 2: 231237.

2. Pucci G, Alcidi R, Tap L, Battista F, Mattace-Raso F, Schillaci G. Sex-and gender-related prevalence, cardiovascular risk and therapeutic approach in metabolic syndrome: A review of the literature. Pharmacol Res. 2017; 120: 34-42.

3. Sherling $\mathrm{DH}$, Perumareddi $\mathrm{P}$, Hennekens $\mathrm{CH}$. Metabolic syndrome: Clinical and policy implications of the new silent killer. J Cardiovasc Pharmacol Ther. 2017; 22: 365-367.

4. Li R, Cui K, Liu K, Li H, Zhang Y, Liu X, et al. Metabolic syndrome in rats is associated with erectile dysfunction by impairing PI3K/Akt/eNOS activity. Sci Reports. 2017; 7: 13464.

5. Jackson $\mathrm{G}$. The metabolic syndrome and erectile dysfunction: Multiple vascular risk factors and hypogonadism. Eur Urol. 2006; 50: 426-427.

6. Kaya E, Sikka SC, Gur S. A comprehensive review of metabolic syndrome affecting erectile dysfunction. J Sex Med. 2015; 12: 856-875.

7. Chaudhary RK, Shamsi BH, Tan T, Chen HM, Xing JP. Study of the relationship between male erectile dysfunction and type 2 diabetes mellitus/metabolic syndrome and its components. J Int Med Res. 2016; 44: 735-741.

8. Reaven GM. Banting lecture 1988. Role of insulin resistance in human disease. Diabetes. 1988; 37: 1595-1607.

9. Saklayen MG. The global epidemic of the metabolic syndrome. Curr Hypertens Rep. 2018; 20: 
12.

10. Lihn AS, Pedersen SB, Richelsen B. Adiponectin: Action, regulation and association to insulin sensitivity. Obes Rev. 2005; 6: 13-21.

11. Kalyani RR, Dobs AS. Androgen deficiency, diabetes, and the metabolic syndrome in men. Curr Opin Endocrinol Diabetes Obes. 2007; 14: 226-234.

12. Devaraj S, Singh U, Jialal I. Human C-reactive protein and the metabolic syndrome. Curr Opin Lipidol. 2009; 20: 182-189.

13. Gorbachinsky I, Akpinar H, Assimos DG. Metabolic syndrome and urologic diseases. Rev Urol. 2010; 12: e157-e180.

14. DeLay KJ, Haney N, Hellstrom WJ. Modifying risk factors in the management of erectile dysfunction: A review. World J Mens Health. 2016; 34: 89-100.

15. Rosen RC, Wing R, Schneider S, Gendrano N. Epidemiology of erectile dysfunction: The role of medical comorbidities and lifestyle factors. Urol Clin. 2005; 32: 403-417.

16. Johannes CB, Araujo AB, Feldman HA, Derby CA, Kleinman KP, McKINLAY JB. Incidence of erectile dysfunction in men 40 to 69 years old: Longitudinal results from the Massachusetts male aging study. J Urol. 2000; 163: 460-463.

17. Patel JP, Lee EH, Mena $\mathrm{Cl}$, Walker CN. Effects of metformin on endothelial health and erectile dysfunction. Transl Androl Urol. 2017; 6: 556-565.

18. Musicki B, Bella AJ, Bivalacqua TJ, Davies KP, DiSanto ME, Gonzalez-Cadavid NF, et al. Basic science evidence for the link between erectile dysfunction and cardiometabolic dysfunction. J Sex Med. 2015; 12: 2233-2255.

19. Moreland RB. Pathophysiology of erectile dysfunction: The contributions of trabecular structure to function and the role of functional antagonism. Int J Impot Res. 2000; 12: S39-S46.

20. Gratzke C, Angulo J, Chitaley K, Dai YT, Kim NN, Paick JS, et al. Anatomy, physiology, and pathophysiology of erectile dysfunction. J Sex Med. 2010; 7: 445-475.

21. Gurbuz N, Gurkan R, Ceylan E, Usta SS, Usta MF. The therapeutic effect of ALT-711 on erectile function in rats treated with high-level AGEs (advanced glycation end products) containing diet. Int J Impot Res. 2021. Doi: 10.1038/s41443-021-00417-8.

22. Gurbuz N, Sagdic G, Sanli A, Ciftcioglu A, Bassorgun I, Baykal A, et al. Therapeutic effect of combination of alagebrium (ALT-711) and sildenafil on erectile function in diabetic rats. Int J Impot Res. 2012; 24: 114-121.

23. Usta MF, Kendirci M, Gur S, Foxwell NA, Bivalacqua TJ, Cellek S, et al. The breakdown of preformed advanced glycation end products reverses erectile dysfunction in streptozotocininduced diabetic rats: Preventive versus curative treatment. J Sex Med. 2006; 3: 242-252.

24. Usta MF, Bivalacqua TJ, Yang DY, Ramanitharan A, Sell DR, Viswanathan A, et al. The protective effect of aminoguanidine on erectile function in streptozotocin diabetic rats. J Urol. 2003; 170: 1437-1442.

25. Musicki B, Kramer MF, Becker RE, Burnett AL. Inactivation of phosphorylated endothelial nitric oxide synthase (Ser-1177) by O-GIcNAc in diabetes-associated erectile dysfunction. Proc Natl Acad Sci U S A. 2005; 102: 11870-11875.

26. Moon KH, Park SY, Kim YW. Obesity and erectile dysfunction: From bench to clinical implication. World J Mens Health. 2019; 37: 138-147.

27. Ruan Y, Zhou J, Kang N, Reed-Maldonado AB, Tamaddon A, Wang B, et al. The effect of lowintensity extracorporeal shockwave therapy in an obesity-associated erectile dysfunction rat 
model. BJU Int. 2018; 122: 133-142.

28. Assaly R, Giuliano F, Clement P, Laurin M, Favier M, Teo P, et al. Extracorporeal shock waves therapy delivered by aries improves erectile dysfunction in spontaneously hypertensive rats through penile tissue remodeling and neovascularization. Sex Med. 2019; 7: 441-450.

29. Bivalacqua TJ, Usta MF, Champion HC, Kadowitz PJ, Hellstrom WJ. Endothelial dysfunction in erectile dysfunction: Role of the endothelium in erectile physiology and disease. J Androl. 2003; 24: S17-S37.

30. Endemann DH, Schiffrin EL. Endothelial dysfunction. J Am Soc Nephrol. 2004; 15: 1983-1992.

31. Nangle MR, Cotter MA, Cameron NE. Effects of rosuvastatin on nitric oxide-dependent function in aorta and corpus cavernosum of diabetic mice: Relationship to cholesterol biosynthesis pathway inhibition and lipid lowering. Diabetes. 2003; 52: 2396-2402.

32. Paskaloglu K, Sener G, Ayanğolu-Dülger G. Melatonin treatment protects against diabetesinduced functional and biochemical changes in rat aorta and corpus cavernosum. Eur J Pharmacol. 2004; 499: 345-354.

33. Elçioğlu KH, Kabasakal L, Cetinel S, Conturk G, Sezen SF, Ayanoğlu-Dülger G. Changes in caveolin1 expression and vasoreactivity in the aorta and corpus cavernosum of fructose and streptozotocin-induced diabetic rats. Eur J Pharmacol. 2010; 642: 113-120.

34. Soner BC, Murat N, Demir O, Guven H, Esen A, Gidener S. Evaluation of vascular smooth muscle and corpus cavernosum on hypercholesterolemia. Is resveratrol promising on erectile dysfunction? Int J Impot Res. 2010; 22: 227-233.

35. Villalba N, Martínez P, Bríones AM, Sánchez A, Salaices M, García-Sacristán A, et al. Differential structural and functional changes in penile and coronary arteries from obese Zucker rats. Am J Physiol Heart Circ Physiol. 2009; 297: H696-H707.

36. Demir O, Murat N, Soner BC, Demir T, Bal E, Can E, et al. Acute effects of hypercholesterolemic diet on erectile responses in rats. Urol Int. 2010; 85: 112-117.

37. La Favor JD, Anderson EJ, Hickner RC, Wingard CJ. Erectile dysfunction precedes coronary artery endothelial dysfunction in rats fed a high-fat, high-sucrose, Western pattern diet. J Sex Med. 2013; 10: 694-703.

38. Park K, Son $\mathrm{H}$, Kim SW, Paick JS. Initial validation of a novel rat model of vasculogenic erectile dysfunction with generalized atherosclerosis. Int J Impot Res. 2005; 17: 424-430.

39. Hannan JL, Blaser MC, Oldfield L, Pang JJ, Adams SM, Pang SC, et al. Morphological and functional evidence for the contribution of the pudendal artery in aging-induced erectile dysfunction. J Sex Med. 2010; 7: 3373-3384.

40. Maio MT, McCabe KM, Pruss CM, Pang JJ, Laverty K, Holden RM, et al. Calcification of the internal pudendal artery and development of erectile dysfunction in adenine-induced chronic kidney disease: A sentinel of systemic vascular changes. J Sex Med. 2014; 11: 2449-2465.

41. Wingard C, Fulton D, Husain S. Altered penile vascular reactivity and erection in the Zucker obese-diabetic rat. J Sex Med. 2007; 4: 343-348.

42. Oltman CL, Richou LL, Davidson EP, Coppey LJ, Lund DD, Yorek MA. Progression of coronary and mesenteric vascular dysfunction in Zucker obese and Zucker diabetic fatty rats. Am J Physiol Heart Circ Physiol. 2006; 291: H1780-H1787.

43. Montorsi P, Ravagnani PM, Galli S, Rotatori F, Briganti A, Salonia A, et al. The artery size hypothesis: A macrovascular link between erectile dysfunction and coronary artery disease. Am J Cardiol. 2005; 96: 19-23. 
44. Jepps TA, Olesen SP, Greenwood IA, Dalsgaard T. Molecular and functional characterization of $\mathrm{Kv} 7$ channels in penile arteries and corpus cavernosum of healthy and metabolic syndrome rats. Br J Pharmacol. 2016; 173: 1478-1490.

45. Elçioğlu HK, Kabasakal L, Özkan N, Çelikel Ç, Ayanoğlu-Dülger G. A study comparing the effects of rosiglitazone and/or insulin treatments on streptozotocin induced diabetic (type I diabetes) rat aorta and cavernous tissues. Eur J Pharmacol. 2011; 660: 476-484.

46. Carneiro FS, Zemse S, Giachini FR, Carneiro ZN, Lima VV, Webb RC, et al. TNF- $\alpha$ infusion impairs corpora cavernosa reactivity. J Sex Med. 2009; 6: 311-319.

47. Kovanecz I, Nolazco G, Ferrini MG, Toblli JE, Heydarkhan S, Vernet D, et al. Early onset of fibrosis within the arterial media in a rat model of type 2 diabetes mellitus with erectile dysfunction. BJU Int. 2009; 103: 1396-1404.

48. Nangle MR, Proietto J, Keast JR. Impaired cavernous reinnervation after penile nerve injury in rats with features of the metabolic syndrome. J Sex Med. 2009; 6: 3032-3044.

49. Sánchez A, Contreras C, Martínez MP, Climent B, Benedito S, García-Sacristán A, et al. Role of neural NO synthase (nNOS) uncoupling in the dysfunctional nitrergic vasorelaxation of penile arteries from insulin-resistant obese Zucker rats. PloS ONE. 2012; 7: e36027.

50. Wang C, Jackson G, Jones TH, Matsumoto AM, Nehra A, Perelman MA, et al. Low testosterone associated with obesity and the metabolic syndrome contributes to sexual dysfunction and cardiovascular disease risk in men with type 2 diabetes. Diabetes Care. 2011; 34: 1669-1675.

51. Blouin K, Boivin A, Tchernof A. Androgens and body fat distribution. J Steroid Biochem Mol Biol. 2008; 108: 272-280.

52. Ding EL, Song Y, Malik VS, Liu S. Sex differences of endogenous sex hormones and risk of type 2 diabetes: A systematic review and meta-analysis. JAMA. 2006; 295: 1288-1299.

53. Keast JR, Saunders RJ. Testosterone has potent, selective effects on the morphology of pelvic autonomic neurons which control the bladder, lower bowel and internal reproductive organs of the male rat. Neuroscience. 1998; 85: 543-556.

54. Traish AM, Goldstein I, Kim NN. Testosterone and erectile function: From basic research to a new clinical paradigm for managing men with androgen insufficiency and erectile dysfunction. Eur Urol. 2007; 52: 54-70.

55. Traish AM, Park K, Dhir V, Kim NN, Moreland RB, Goldstein I. Effects of castration and androgen replacement on erectile function in a rabbit model. Endocrinology. 1999; 140: 1861-1868.

56. Iacono F, Prezioso D, Ruffo A, Illiano E, Romis L, Di Lauro G, et al. Testosterone deficiency causes penile fibrosis and organic erectile dysfunction in aging men. Evaluating association among Age, TDS and ED. BMC Surg. 2012; 12: S24.

57. Traish A, Kim N. The physiological role of androgens in penile erection: Regulation of corpus cavernosum structure and function. J Sex Med. 2005; 2: 759-770.

58. Baba K, Yajima M, Carrier S, Morgan DM, Nunes L, Lue TF, et al. Delayed testosterone replacement restores nitric oxide synthase-containing nerve fibres and the erectile response in rat penis. BJU Int. 2000; 85: 953-958.

59. Mills TM, Stopper VS, Wiedmeier VT. Effects of castration and androgen replacement on the hemodynamics of penile erection in the rat. Biol Reprod. 1994; 51: 234-238.

60. Aversa A, Isidori AM, De Martino MU, Caprio M, Fabbrini E, Rocchietti-March M, et al. Androgens and penile erection: Evidence for a direct relationship between free testosterone and cavernous vasodilation in men with erectile dysfunction. Clin Endocrinol. 2000; 53: 517-522. 
61. Traish AM, Toselli P, Jeong SJ, Kim NN. Adipocyte accumulation in penile corpus cavernosum of the orchiectomized rabbit: A potential mechanism for veno-occlusive dysfunction in androgen deficiency. J Androl. 2005; 26: 242-248.

62. Filippi S, Vignozzi L, Morelli A, Chavalmane AK, Sarchielli E, Fibbi B, et al. Testosterone partially ameliorates metabolic profile and erectile responsiveness to PDE5 inhibitors in an animal model of male metabolic syndrome. J Sex Med. 2009; 6: 3274-3288.

63. Esposito K, Giugliano F, Martedì E, Feola G, Marfella R, D’Armiento M, et al. High proportions of erectile dysfunction in men with the metabolic syndrome. Diabetes Care. 2005; 28: 1201-1203.

64. Bal K, Öder M, Şahin AS, Karataş CT, Demir Ö, Can E, et al. Prevalence of metabolic syndrome and its association with erectile dysfunction among urologic patients: Metabolic backgrounds of erectile dysfunction. Urology. 2007; 69: 356-360.

65. Sattar N, Gaw A, Scherbakova O, Ford I, O’Reilly DS, Haffner SM, et al. Metabolic syndrome with and without C-reactive protein as a predictor of coronary heart disease and diabetes in the West of Scotland coronary prevention study. Circulation. 2003; 108: 414-419.

66. Raheem OA, Su JJ, Wilson JR, Hsieh TC. The association of erectile dysfunction and cardiovascular disease: A systematic critical review. Am J Mens Health. 2017; 11: 552-563.

67. Shamloul R, Ghanem HM, Salem A, Elnashaar A, Elnaggar W, Darwish H, et al. Correlation between penile duplex findings and stress electrocardiography in men with erectile dysfunction. Int J Impot Res. 2004; 16: 235-237.

68. Grover SA, Lowensteyn I, Kaouache M, Marchand S, Coupal L, DeCarolis E, et al. The prevalence of erectile dysfunction in the primary care setting: Importance of risk factors for diabetes and vascular disease. Arch Intern Med. 2006; 166: 213-219.

69. Lane-Cordova AD, Kershaw K, Liu K, Herrington D, Lloyd-Jones DM. Association between cardiovascular health and endothelial function with future erectile dysfunction: The multiethnic study of atherosclerosis. Am J Hypertens. 2017; 30: 815-821.

70. Giugliano F, Esposito K, Di Palo C, Ciotola M, Giugliano G, Marfella R, et al. Erectile dysfunction associates with endothelial dysfunction and raised proinflammatory cytokine levels in obese men. J Endocrinol Invest. 2004; 27: 665-669.

71. Creager MA, Lüscher TF, prepared with the assistance of, Cosentino F, Beckman JA. Diabetes and vascular disease: Pathophysiology, clinical consequences, and medical therapy: Part I. Circulation. 2003; 108: 1527-1532.

72. Rosen RC, Wing RR, Schneider S, Wadden TA, Foster GD, West DS, et al. Erectile dysfunction in type 2 diabetic men: Relationship to exercise fitness and cardiovascular risk factors in the Look AHEAD trial. J Sex Med. 2009; 6: 1414-1422.

73. Weinberg AE, Eisenberg M, Patel CJ, Chertow GM, Leppert JT. Diabetes severity, metabolic syndrome, and the risk of erectile dysfunction. J Sex Med. 2013; 10: 3102-3109.

74. Khaw KT, Barrett-Connor E. Blood pressure and endogenous testosterone in men: An inverse relationship. J Hypertens. 1988; 6: 329-332.

75. Phillips GB, Jing T, Heymsfield SB. Relationships in men of sex hormones, insulin, adiposity, and risk factors for myocardial infarction. Metabolism. 2003; 52: 784-790.

76. Haffner SM, Valdez RA, Mykkänen L, Stern MP, Katz MS. Decreased testosterone and dehydroepiandrosterone sulfate concentrations are associated with increased insulin and glucose concentrations in nondiabetic men. Metabolism. 1994; 43: 599-603.

77. Selvin E, Feinleib M, Zhang L, Rohrmann S, Rifai N, Nelson WG, et al. Androgens and diabetes in 
men: Results from the Third National Health and Nutrition Examination Survey (NHANES III). Diabetes Care. 2007; 30: 234-238.

78. Laaksonen DE, Niskanen L, Punnonen K, Nyyssonen K, Tuomainen TP, Salonen R, et al. Sex hormones, inflammation and the metabolic syndrome: A population-based study. Eur J Endocrinol. 2003; 149: 601-608.

79. Atlantis E, Martin SA, Haren MT, O'Loughlin PD, Taylor AW, Anand-Ivell R, et al. Demographic, physical and lifestyle factors associated with androgen status: The Florey Adelaide Male Ageing Study (FAMAS). Clin Endocrinol. 2009; 71: 261-272.

80. Kapoor D, Clarke S, Stanworth R, Channer KS, Jones TH. The effect of testosterone replacement therapy on adipocytokines and C-reactive protein in hypogonadal men with type 2 diabetes. Eur J Endocrinol. 2007; 156: 595-602.

81. Corona G, Mannucci E, Ricca V, Lotti F, Boddi V, Bandini E, et al. The age-related decline of testosterone is associated with different specific symptoms and signs in patients with sexual dysfunction. Int J Androl. 2009; 32: 720-728.

82. Cohen PG. Obesity in men: The hypogonadal-estrogen receptor relationship and its effect on glucose homeostasis. Medical Hypotheses. 2008; 70: 358-360.

83. Shiri R, Koskimäki J, Hakama M, Häkkinen J, Huhtala $H$, Tammela TL, et al. Effect of life-style factors on incidence of erectile dysfunction. Int J Impot Res. 2004; 16: 389-394.

84. Khoo J, Piantadosi C, Worthley S, Wittert GA. Effects of a low-energy diet on sexual function and lower urinary tract symptoms in obese men. Int J Obes. 2010; 34: 1396-1403.

85. Reis LO, Favaro WJ, Barreiro GC, De Oliveira LC, Chaim EA, Fregonesi A, et al. Erectile dysfunction and hormonal imbalance in morbidly obese male is reversed after gastric bypass surgery: $A$ prospective randomized controlled trial. Int J Androl. 2010; 33: 736-744.

86. Cheng JY, Ng EM, Ko JS, Chen RY. Physical activity and erectile dysfunction: Meta-analysis of population-based studies. Int J Impot Res. 2007; 19: 245-252.

87. Derby CA, Mohr BA, Goldstein I, Feldman HA, Johannes CB, McKinlay JB. Modifiable risk factors and erectile dysfunction: Can lifestyle changes modify risk? Urology. 2000; 56: 302-306.

88. Gerbild H, Larsen CM, Graugaard C, Josefsson KA. Physical activity to improve erectile function: A systematic review of intervention studies. Sex Med. 2018; 6: 75-89.

89. Esposito K, Ciotola M, Giugliano F, De Sio M, Giugliano G, D'armiento M, et al. Mediterranean diet improves erectile function in subjects with the metabolic syndrome. Int J Impot Res. 2006; 18: 405-410.

90. Tsunekawa T, Hayashi T, Kano H, Sumi D, Matsui-Hirai H, Thakur NK, et al. Cerivastatin, a hydroxymethylglutaryl coenzyme a reductase inhibitor, improves endothelial function in elderly diabetic patients within 3 days. Circulation. 2001; 104: 376-379.

91. Jing $Y$, Wu F, Li D, Yang L, Li Q, Li R. Metformin improves obesity-associated inflammation by altering macrophages polarization. Mol Cell Endocrinol. 2018; 461: 256-264.

92. Vitale C, Mercuro G, Cornoldi A, Fini M, Volterrani M, Rosano GM. Metformin improves endothelial function in patients with metabolic syndrome. J Intern Med. 2005; 258: 250-256.

93. Rey-Valzacchi GJ, Costanzo PR, Finger LA, Layus AO, Gueglio GM, Litwak LE, et al. Addition of metformin to sildenafil treatment for erectile dysfunction in eugonadal nondiabetic men with insulin resistance. A prospective, randomized, double-blind pilot study. J Androl. 2012; 33: 608614. 


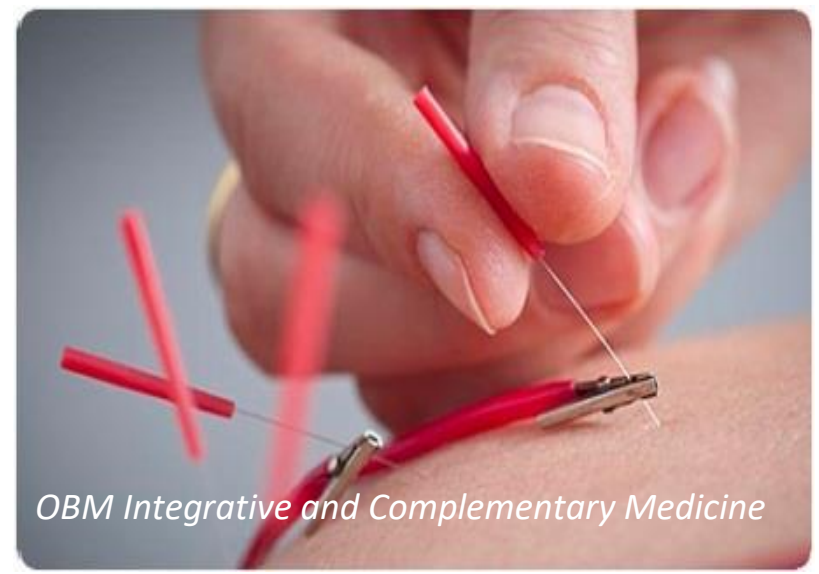

Enjoy OBM Integrative and Complementary Medicine by:

1. Submitting a manuscript

2. Joining in volunteer reviewer bank

3. Joining Editorial Board

4. Guest editing a special issue

For more details, please visit:

http://www.lidsen.com/journals/icm 